\title{
O LUGAR DO AFETIVO NO DESENVOLVIMENTO DA CRIANÇA: IMPLICAÇÕES EDUCACIONAIS
}

\author{
Cláudia Aparecida Valderramas Gomes ${ }^{1}$ \\ Universidade Estadual Paulista Júlio de Mesquita Filho, Assis-SP, Brasil
}

\begin{abstract}
RESUMO. Este estudo, de natureza teórica, tem por objetivo analisar algumas proposições da Psicologia Histórico-Cultural acerca do psiquismo humano, notadamente no que tange à constituição dos processos afetivos na relação com o desenvolvimento infantil. Para tanto, reúne alguns princípios da filosofia spinosiana que fundamentaram o pensamento de Vigotski sobre os afetos e postula que, para essa escola da psicologia, na base da formação humana se encontram a experiência social e a relação sujeito-objeto, elementos constitutivos dos processos cognitivo e afetivo. As análises desenvolvidas ao longo do texto indicam que os mediadores sociais signos e instrumentos - subsidiam a formação da atividade e da consciência num processo que legitima a origem histórica e social das funções afetivas. O artigo pretende evidenciar o papel da escola como um espaço privilegiado de acesso aos conhecimentos capazes de transformar os modos de pensar, sentir e agir das crianças por meio dos processos de ensino e de aprendizagem.
\end{abstract}

Palavras-chave: Psicologia histórico-cultural; afetos; desenvolvimento infantil.

\section{THE PLACE OF AFFECTIVE ON CHILD DEVELOPMENT: EDUCATIONAL IMPLICATIONS}

\begin{abstract}
This study, of theoretical nature, aims to analyse some propositions of Historic and Cultural psychology about human psyche, especially regarding the constitution of affective processes in relation to child development. Therefore, brings together some principles of Spinozist philosophy that underlie the Vigotskian thought about affections and postulates that, for this school of psychology, on the basis of human development are the social experience and subject-object relation, constitutive of cognitive and affective processes. The analyses developed over the text indicate that social mediators - signs and instruments - subsidize the formation of activity and consciousness in a process that legitimizes the historic and social origin of affective functions. The paper aims to highlight the role of education as a privileged place of access to knowledge capable of transforming ways of thinking, feeling and acting of children through the processes of teaching and learning.
\end{abstract}

Key words: Historical and cultural psychology; affections; childhood development.

\section{EL LUGAR DEL AFECTIVO EN EL DESARROLLO DEL NIÑO: IMPLICACIONES EDUCATIVAS}

RESUMEN. Este estudio, de naturaleza teórica, tiene como objetivo analizar algunas proposiciones de la psicología Histórico-Cultural acerca del psiquismo humano, especialmente en lo que se refiere a la constitución de los procesos afectivos en la relación con el desarrollo infantil. Para ello, reúne algunos principios de la filosofía spinozista que fundamentaron el pensamiento vigotskiano sobre los afectos y postula que, para esta escuela de la psicología, en la base de la formación humana se encuentran la experiencia social y la relación sujeto-objeto, constitutivas de los procesos cognitivos y afectivos. Los análisis desarrollados a lo largo del texto indican que los mediadores sociales signos e instrumentos - subvencionan la formación de la actividad y de la conciencia en un proceso que legitima el origen histórico y social de las funciones afectivas. El artículo pretende evidenciar el papel de la educación escolar como un espacio privilegiado de acceso a los conocimientos capaces de transformar las formas de pensar, sentir y actuar de los niños por medio de los procesos de enseñanza y aprendizaje.

Palabras-clave: Psicología histórico-cultural; afectos; desarrollo infantil.

1 Endereço para correspondência: Rua Antonio do Espírito Santo, 8/18, Bairro Paraíso - CEP 17.051-180 - BauruSP.E-mail: cabegomes@uol.com.br 
Podemos afirmar que o conhecimento não se assenta apenas sobre bases cognitivas? Quais elementos estão postos entre o sujeito e os objetos do conhecimento que, perpassando a aprendizagem, movimentam o desenvolvimento humano? Dizer que o afetivo ${ }^{2}$ se conjuga ao cognitivo na explicação da aprendizagem é uma afirmação corrente para a maioria das pessoas e até mesmo um consenso entre educadores; mas, efetivamente, qual é o fundamento dessa relação na explicação da atividade humana e, consequentemente, na constituição do conhecimento ou da consciência do sujeito? Essas são questões que buscamos responder durante o trabalho desenvolvido como tese de doutorado e que, agora, gostaria de compartilhar com o leitor, convidando-o a refletir acerca das considerações que aquele estudo protagonizou e que julgo serem importantes na condução do pensar e do fazer pedagógico na Educação Infantil.

Entre os equívocos que permanecem acompanhando muitos dos problemas enfrentados pelas crianças no contexto escolar, ainda persiste um modo de pensar os processos afetivos que os associa frequentemente a experiências vividas pela criança na sua primeira infância, a traços de personalidade ou à estrutura e dinâmica familiares que, ao interferirem na aprendizagem, acabam "perturbando" seu desenvolvimento intelectual. Outro equívoco - resultante da fragmentação entre afetivo e cognitivo - é o fato de a escola pensar as experiências afetivas como algo que acontece fora dela, elegendo o cognitivo como seu único espaço de atuação. Isto reforça a ideia, ainda presente, de que os afetos acontecem separados das demais funções psíquicas que conformam a personalidade humana. Por isso prevalece na escola a opinião de que as emoções são prejudiciais, um impedimento que, por vezes, atrapalha o processo de escolarização das crianças, o que contribui para a naturalização do afetivo no terreno da educação escolar (Gomes, 2008).

Para superar tais ideias buscamos em outros estudos (Mangiolino, 2010; Gomes \& Mello, 2010; Toassa, 2009; Gomes, 2008) baseados na

2 O adjetivo afetivo será empregado neste texto conforme a atribuição filosófica, que designa em geral tudo o que se refere à esfera das emoções: estado, função ou condição de caráter genericamente emotivo, podendo referir-se a qualquer emoção, afeto ou paixão (Abbagnano, 2007, p. 20).
Psicologia Histórico-Cultural, argumentos que explicitassem a constituição dos processos afetivos como resultado da história de apropriação e objetivação de signos e instrumentos que cada sujeito realiza ao longo de sua vida. Vale destacar que, segundo Mangiolino (2010), a questão central da obra de Vigotski diz respeito ao desenvolvimento das emoções, (trans)formadas pelo signo na história socioindividual. Esse aporte teórico contribuiu para a desconstrução da visão de potenciais inatos, predisposições e tendências afetivas, colocando, na organização e condução da prática pedagógica, a educação escolar e o caráter intencional do trabalho docente como elementos determinantes da transformação dos modos de pensar e sentir de cada criança. Assim, buscamos neste texto analisar algumas proposições da Psicologia Histórico-Cultural acerca do psiquismo humano, especialmente no que tange à constituição dos processos afetivos e a como estes se põem na relação com o desenvolvimento da criança, refletindo sobre o papel da educação escolar.

Entender a constituição dos processos afetivos e a unidade entre afeto e cognição mediadora nas relações da criança com o conhecimento - nos coloca a possibilidade de, neste capítulo, estimular o leitor a acompanhar nossa reflexão a propósito das forças que exercem a educação escolar e a figura do professor na formação integral do sujeito. Buscamos apreender alguns elementos que poderão se converter em mediadores entre a teoria e a prática escolar diária, determinando outro patamar na compreensão que temos da atividade da criança e na ação que empreendemos tendo em vista seu processo de aprendizagem e desenvolvimento.

É importante mencionar que o exercício de pensar a respeito do afetivo no desenvolvimento humano nos colocou dois desafios. O primeiro foi o de romper com o significado do termo afeto no senso comum, que remete a afeição e carinho, e buscar o que este termo representa do ponto de vista filosófico (Martins, 2009); e o segundo, o de superar uma visão estritamente biológica e buscar uma compreensão histórica e social que os processos afetivos adquirem no psiquismo humano. Não obstante, é preciso dizer que esta superação só foi possível com o auxílio do próprio conhecimento filosófico, o qual permitiu suplantar a dicotomia corpo e mente tendo como base o conceito de afeto. 
No bojo de algumas concepções equivocadas, a psicologia tradicional foi estabelecendo outras dicotomias atualmente presentes na educação escolar. Um exemplo disso é que na escola tratamos afeto e cognição como se fossem dois elementos separados na pessoa que aprende. Da mesma forma, falamos das emoções como se elas fossem isoladas do processo de aprendizagem. Compreender o afetivo desse ponto de vista traz consequências para o trabalho pedagógico: adotamos uma visão estática e uniforme da motivação, o que significa que as necessidades, os desejos e interesses das crianças - que têm como fundamento os processos afetivos - são vistos como aspectos naturais, intrínsecos à sua personalidade, portanto, independentes da história de apropriações e objetivações do sujeito.

Sendo assim, a aprendizagem ou não aprendizagem dos conteúdos escolares depende da motivação que o sujeito já tenha para aprender. Quando pensamos dessa maneira, a educação tem pouco a fazer para estabelecer uma relação entre o sujeito e o conhecimento, uma vez que, ou o sujeito já tem uma motivação para aprender, ou então, na escola tentamos criar apenas uma motivação temporária.

Foi por meio dos estudos desenvolvidos pela escola soviética de Psicologia, representada, principalmente por Lev Semiónovich Vigotski (1896-1934), fundamentado nos pressupostos teórico-filosóficos e metodológicos do Materialismo Histórico-Dialético, que teve início um movimento de superação das diversas dicotomias - natural-histórico, objetivo-subjetivo, social-individual, afetivo-cognitivo - criadas ao longo da história pela ciência na tentativa de explicar o ser humano e suas características. Romper com esses dualismos na maneira de conceber a realidade social e humana incluía pensar na constituição dos processos afetivos no conjunto do desenvolvimento humano.

\section{A CONSTITUIÇÃO DOS PROCESSOS AFETIVOS NA PERSPECTIVA HISTÓRICO-CULTURAL}

Vigotski $(1995,1996)$ explica os fenômenos e processos psicológicos a partir de sua história e interdependência. Coerente com os fundamentos filosóficos da sua teoria, ele propõe a indissociabilidade de cada uma das funções psíquicas no desenvolvimento da personalidade humana, enfatizando que existem diferenças significativas nos processos afetivos quando comparamos criança e adulto. Esse autor reitera que tais processos sofrem mudanças qualitativas à medida que $o$ sujeito avança no desenvolvimento das demais funções psíquicas, como a percepção, a atenção, a memória, o pensamento, a linguagem e a vontade.

Destaca aquele psicólogo que, se os processos afetivos estão conectados a outras funções psicológicas e ao desenvolvimento da consciência como um todo, o lugar social que a criança ocupa no contexto das suas relações, suas experiências culturais e interações sociais constituem fatores indispensáveis para se compreender a dinâmica e o desenvolvimento desses processos. Afirma, ainda, que as emoções sofrem mudanças qualitativas ao longo do desenvolvimento da criança em decorrência de seu crescente domínio de instrumentos culturais, entre os quais se destaca a linguagem, que constitui uma conquista do sujeito: maior controle sobre si mesmo, sobre sua própria conduta.

Vigotski (1996) esclarece que, desde o nascimento, por ter se separado fisicamente do organismo da mãe, a criança já se encontra inserida num contexto humano e social, e reconhece que o recém-nascido possui, no seu grau mais primitivo, rudimentos de vida psíquica, porém essa manifestação está associada a um funcionamento dos centros mais primitivos do cérebro, os subcorticais, e, como o cérebro está ainda imaturo, os instintos e afetos mais simples ficam dependentes dessas instâncias menos desenvolvidas do sistema nervoso.

O que existe como estado rudimentar da vida psíquica no recém-nascido é um embrião de consciência: estados nebulosos, confusos, nos quais o sensitivo e o emocional se acham fundidos. Isso significa que, nesta etapa da vida, tudo aquilo que o bebê percebe do meio está unido com o afeto; para ele, a percepção do que é agradável ou ameaçador aparece muito antes do que os elementos objetivos da realidade exterior. Vigotski (1996) define esta relação da criança com o mundo como "estados sensitivos emocionais ou estados de sensações marcadas emocionalmente" (p.281). Por causa desse modo de pensar as emoções - como inicialmente ligadas aos setores menos desenvolvidos do cérebro - é que as teorias vigentes na psicologia tradicional ainda pressupõem que os processos afetivos, em geral, são próprios de uma psique primitiva, como um estágio inferior do 
desenvolvimento - $\quad$ dimensão pouco desenvolvida no conjunto da personalidade humana - referindo-se a ela como uma instância que contém elementos remotos da existência animal (Vigotski, 2003).

Contrariando esse ponto de vista, o autor russo $(1996,2003)$ afirma que o estágio inicial e primitivo do desenvolvimento da consciência não se diferencia dos demais pela importância das tendências afetivas, uma vez que, segundo ele, o afeto se mantém essencial ao longo de todo o desenvolvimento da criança; ou seja, ele defende que os afetos primitivos são superiores apenas quando as demais funções psíquicas (sensoriais, intelectuais e motoras) ainda não estão desenvolvidas. Os impulsos afetivos são o acompanhante permanente de cada nova etapa no desenvolvimento da criança, desde a inferior até a mais elevada. O afeto inicia e encerra o processo de desenvolvimento psíquico da criança, a formação de sua personalidade, perpassando assim todo o seu desenvolvimento.

Assim, não é casual as funções afetivas estarem em relação direta tanto com os centros subcorticais mais antigos, que são os primeiros a se desenvolver e se encontram na base do cérebro, como as formações cerebrais mais novas e especificamente humanas, os lóbulos frontais, que são os últimos a configurar-se. Como afirma o psicólogo russo, "o afeto é o alfa e o ômega, o primeiro e o último elo, o prólogo e o epílogo de todo o desenvolvimento psíquico" (Vygotski, 1996, p. 299).

Isto posto, para compreender a dinâmica relação entre os processos afetivos e cognitivos precisamos, primeiramente, compreender o psiquismo humano como um sistema complexo que funciona relacionando processos biológicos, psicológicos e sociais e que tem nas categorias de atividade e consciência seu núcleo de sustentação e desenvolvimento.

\section{OS MEDIADORES SOCIAIS E A FORMAÇÃO DO PSIQUISMO HUMANO}

O psiquismo humano, também denominado reflexo psíquico da realidade (Leontiev, 1978a), compreende um substrato material, orgânico e natural como ponto de partida: o cérebro humano, materialidade sobre a qual se dá o desenvolvimento psicológico do sujeito e que principia por uma atividade psíquica que acontece em função do mundo exterior, respondendo a uma ação que este mundo exerce sobre o sujeito. Sendo assim, atividade psíquica é atividade reflexa.

O reflexo psíquico da realidade é consciente, já que a consciência é uma qualidade essencial, um atributo do nosso psiquismo. Como afirmava Marx (1993), "o modo como a consciência é e como algo para ela existe é o conhecer" (p. 252), contudo é preciso considerar o desenvolvimento da consciência ao longo de um processo, já que esta não pode ser tomada como "algo que já está dentro" do sujeito desde que ele nasce, mas como resultado de sua atividade no mundo objetivo. A relação sujeito-objeto é a base sobre a qual se constitui o reflexo psíquico da realidade, e os mediadores sociais (signos e instrumentos) exercem papel determinante na constituição das funções psicológicas superiores, as quais, na verdade, só se concretizam por meio da atividade social do sujeito.

Friedrich (2012) contribui com essa argumentação afirmando que Vigotski propõe o psiquismo como um conceito psicológico de base, comparando-o "a um instrumento que isola, separa, abstrai, faz escolhas dos fatos da realidade" (p.47). A autora reforça que, conforme Vigotski, nossos sentidos nos aproximam e nos fazem perceber, fundamentalmente, as partes da realidade que são importantes para nós. Afirma:

Ele fala de órgão de seleção, de filtro ....
Todos esses "instrumentos" têm uma
função em comum, a saber, a de
"escolher", de selecionar, de deixar
passar determinados elementos da
realidade e de reter outros. É por essa
razão que Vigotski considera o
psiquismo como a forma superior de
escolha e atribui a essa característica
um valor exclusivamente positivo.
(Friedrich, 2012, p. 48)

Neste processo, à medida que amplia e elabora sua atividade ao lidar com os objetos e fenômenos da realidade, o ser humano vai formando as suas funções psíquicas superiores, ou seja, a memória e a atenção tornam-se voluntárias, o pensamento se complexifica e ele pode dominar a própria conduta. Isso tudo permite um reflexo cada vez mais sofisticado da realidade. Trata-se de conceber o reflexo psíquico como efeito da relação sujeito-objeto, e "é nessa complexa trama que se dá o processo de apropriação-objetivação pelo sujeito e que se constituem as funções cognitivas e as funções afetivas" (Gomes, 2008, p. 115). 
A objetivação é síntese da atividade humana. Leontiev (1978b) explica que cada nova geração inicia sua vida num ambiente repleto de objetos e de fenômenos criados pelas gerações antecedentes e cada sujeito deverá se apropriar das riquezas desse mundo participando das diversas formas de atividade social, e é só por meio dessa participação ativa que ele poderá vir a desenvolver as aptidões e capacidades especificamente humanas que se encontram cristalizadas nos objetos sociais. Ao se apropriar de uma objetivação, o indivíduo está se relacionando com a história social, ainda que tal relação não seja consciente para ele; portanto, a apropriação do significado social de uma objetivação é um processo de inserção na continuidade da história das gerações e um pressuposto para a formação da sua individualidade.

A observação do desenvolvimento da criança nos mostra que o bebê, por volta do segundo mês de vida, já começa um movimento de orientação até o adulto. Esse movimento não é natural e espontâneo, mas estimulado pelo adulto, que, ao aproximar-se dele, conversa, aponta objetos, oferece o alimento, conforta, enfim propõe situações por meio das quais o bebê manifesta ações indicativas do desejo de uma relação de contato. Essa relação cria no bebê uma necessidade que ele não tinha até então e que passa a ter a partir do contato e das sucessivas aproximações que estabelece com o adulto; a necessidade do "outro" é, portanto, uma necessidade socialmente criada. Desse momento em diante surgem as condições para a experiência com objetos que, associada ao balbucio, indica que a passividade do recémnascido em relação ao mundo é substituída por um interesse receptivo: a criança começa a entregar-se à influência dos estímulos externos.

No primeiro ano de vida, a existência social da criança é, desde os primeiros contatos entre o adulto e o bebê, uma relação mediada pelos objetos, da mesma forma que a sua própria relação com os objetos requer a mediação dos adultos. É o adulto quem apresenta o objeto para a criança, mostra seu funcionamento e suas qualidades. Neste mesmo processo, a linguagem verbal é apresentada à criança e cria nela uma nova necessidade: a comunicação oral, que, inicialmente, tem a função de socializar os significados atribuídos aos objetos e fenômenos.
Uma característica do comportamento da criança na primeira infância é o modo como ela depende da situação presente. Diferentemente de crianças mais velhas, a criança pequena não traz para a situação conhecimentos prévios sobre as coisas; por isso o que ela vê a influencia muito e os objetos adquirem um caráter imperativo, um caráter de "afeto coercitivo": "É como se de cada objeto emanasse um afeto de atração ou repulsão que é o motivo que estimula a criança" (Vygotski, 1996, p. 341).

De acordo com Mukhina (1995), desde bem pequena a criança já demonstra em suas ações certa disposição para um objetivo específico. Nesta fase o que a atrai, controla e determina sua atenção são principalmente os objetos. Pelo fato de ela não conseguir perceber e elaborar ou organizar o percebido com a ajuda da atenção, da memória e do pensamento, pois estas funções ainda não estão diferenciadas, ocorre o predomínio do afetivo na formação da sua consciência.

\section{A GÊNESE DOS PROCESSOS AFETIVOS: ATIVIDADE E CONSCIÊNCIA}

A consciência tem a função de dirigir a atividade do sujeito visando à satisfação de suas necessidades biológicas, tanto quanto das novas necessidades que ele mesmo vai criando em face das relações num certo contexto. Assim, atividade e consciência mantêm entre si uma relação dinâmica e de dependência recíproca, por meio da qual a consciência cumpre a função reguladora da atividade, e nesse processo o afeto participa como a base do registro subjetivo, como um efeito que as influências externas exercem sobre a vida psíquica do sujeito.

Para explicar a constituição dos processos afetivos na atividade e consciência do sujeito, Vigotski (2004) utiliza os fundamentos filosóficos da teoria de Spinosa, referência na análise histórico-psicológica que aquele autor realiza sobre as emoções. Em sua obra, o filósofo explica a relação entre o corpo e a alma, bem como a natureza, a origem e a essência da alma, da razão e dos afetos, categorias importantes para a análise da unidade entre afeto e cognição na formação da consciência. "Ao associar, inextricavelmente, pensamento e afeto, ao definir a mente como ideia do corpo e insistir que o humano jamais se desvincula da natureza, Spinoza rompe com dualismos persistentes em nossa história ocidental" (Merçon, 2009, p.19). 
Para a filosofia spinosiana, a consciência, denominada alma, surge a partir da vivência e/ou experiência, por parte do sujeito, de uma afecção (affectio), que é a ação de um objeto qualquer sobre o seu corpo. Uma afecção representa as ações dos outros corpos e ideias sobre nós, determinando a possibilidade do conhecimento; e uma vez que a consciência é, por definição, um sistema de conhecimentos, ela dependerá das afecções ou de como o sujeito é afetado e percebe os objetos e fenômenos, assim como as pessoas que se relacionam com ele.

\begin{abstract}
Afeto diz respeito àquilo que afeta, ao que mobiliza, por isso reporta à sensibilidade, às sensações. Podemos, ainda, referir afeto como ser tomado por, atravessado, perpassado, quer dizer: afetado. Esse atravessar, perpassar é o que propriamente dá o caráter de afecção (Gomes \& Mello, 2010, p.684).
\end{abstract}

Quando o sujeito experiencia uma afecção, essa vivência provoca uma alteração da sua potência de pensar e agir que deve ser apreendida como um esforço do sujeito que se manifesta diferentemente segundo os objetos encontrados. Do efeito decorrente do encontro de algum objeto (corpo, fenômeno ou ideia) com o nosso corpo emerge um sentimento de variação dessa potência de agir e de pensar que não pode ser confundida com possibilidade, préformação, predeterminação ou preexistência, mas que acontece, necessariamente, na atividade; ou seja, ao se deparar com um objeto que Ihe chama a atenção, a criança mobiliza as funções já desenvolvidas em sua experiência anterior para manipular, perceber e compreender esse objeto. Para a teoria de Spinosa, o afeto pode ser definido como um regime de variação que acontece à medida que vamos experienciando objetos, acontecimentos, ideias (Deleuze, 1978).

O filósofo adverte que essa flutuação das potências de agir e de pensar - ora podendo elevar-se, determinando um estado de alegria, ora diminuir, causando a tristeza - depende do modo como se dá a relação sujeito-objeto, que é sempre mediada pelas relações anteriores da criança com os objetos e com as pessoas.

O tratamento dispensado por Espinosa à relação entre afecção (affectio) e afeto (affectus) nos remete à relação sujeitoobjeto, uma vez que a afecção indica a ação do objeto sobre o sujeito enquanto o afeto, como indutor da potência de agir, nos remete à ação do sujeito sobre o objeto (Gomes, 2008, p. 74)

Pensemos na criança ainda bem pequena que acabou de aprender a andar. Essa nova aquisição tende a aumentar sua capacidade de conhecer o mundo e os objetos que a cercam. Ela empreende um grande esforço para manter o equilíbrio, para se deslocar, desviar-se dos objetos e atingir o objetivo desejado. Quando a criança é incentivada e reforçada por aqueles que estão a seu redor, ela vence o medo de cair e consegue, pouco a pouco, dominar seu próprio corpo e aumentar o poder sobre si mesma.

Mukhina (1995) refere que essa primeira etapa da aprendizagem do andar é vista pela criança como "uma missão muito especial que Ihe proporciona fortes emoções ... Às vezes a alegria é tão grande que começa a agitar as mãos e, claro, cai. Mas esses episódios não diminuem seu desejo de andar, nem turvam sua alegria" (p.104). Diferentemente, há crianças que, por serem tolhidas em suas iniciativas, tão logo iniciam o exercício do andar, experimentam um nível maior de tensão, do que resulta uma diminuição dessa capacidade e um ritmo diferente no desenvolvimento das habilidades de orientação no espaço e autonomia.

A afirmação de Mello (2006) ilustra essa variação das potências na relação essencialmente emocional - entre criança e adulto no início deste processo reiterando que essa dinâmica caracteriza o modo como os afetos se consolidam na atividade dos sujeitos ao longo de todo o ciclo de vida. Diz a autora:

[a relação] sendo positiva, possibilita
uma vivência agradável entendida como
um convite à ampliação da relação com
o mundo de pessoas e objetos ao redor.
Sendo negativa, inibe a iniciativa da
criança. Em lugar de abrir-se para o
mundo que se descortina frente a ela, a
criança se fecha. (p.199)

As afecções determinam as possibilidades do conhecimento por parte do sujeito, portanto a noção de afeto nos remete à noção de encontro. Com base em nossas vivências e em nossa relação com os objetos é que os afetos acontecem. "Pensaremos o aprendizado afetivo como uma arte do encontro: um aprender sobre o que diminui nossas forças ou nos potencializa" (Merçon, 2009, p. 28). 
Assim, é oportuno afirmar que o desejo nos motiva a agir diferentemente conforme os objetos que encontramos, portanto devemos dizer que o desejo está, a cada instante, condicionado pelas afecções (efeitos) que nos vêm dos objetos e das relações que estabelecemos com as pessoas. A consciência emerge, consequentemente, como o sentimento contínuo dessas variações em função dos objetos e ideias que afetam o sujeito durante sua existência.

Se o que caracteriza a função de conhecimento da consciência é sua interconexão com a atividade, este processo que articula os processos cognitivos e afetivos, determinando a formação da consciência e sua objetivação sob a forma de atividade humana, aponta para o sentido como uma categoria que sintetiza o sentir, o pensar e o fazer. A propósito da integração do afetivo na vida psíquica do sujeito como um processo por meio do qual o afeto ganha sentido subjetivo, González Rey (2003) afirma que "uma experiência ou ação só tem sentido quando é portadora de uma carga emocional" (p. 349). Cabe-nos, então, refletir um pouco acerca do papel que os processos afetivos desempenham na atividade do sujeito.

A emoção caracteriza o estado do sujeito ante toda a ação, ou podemos dizer que as emoções encontram-se estreitamente associadas às ações que o indivíduo realiza no conjunto das suas relações sociais; portanto, o que define a disposição do sujeito para atuar são os processos afetivo-emocionais. O sentimento de variação (elevação ou diminuição) das potências de pensar e agir é que determina a orientação do sujeito para esta ou aquela direção, indicando sua atividade ou passividade. Para exemplificar como os processos afetivos condicionam nossa atividade, vale mencionar o relato de uma criança com dificuldades de aprendizagem que distinguiu o medo que sentia da mãe do medo que sentia da professora:

O primeiro era bom, pois a mãe, apesar de repreender e castigar a filha, acreditava que ela tinha capacidade para estudar. Esse medo gerava ação, incentivava a superação do problema. $O$ segundo era ruim, "pavoroso", já que reforçado pela humilhação e vergonha provocadas pelo olhar da professora, causava um estado de imobilidade (Sawaia, 2003, p.58).
Mesmo afirmando que os processos afetivos, em sua qualidade subjetiva, evidenciam o modo como o interno e o externo se articulam de forma a permitir sua constituição, ainda fica por explicar qual é a condição interna do sujeito que se faz sensível ao registro emocional e o que impulsiona a sua ação diante de um objeto ou situação. A necessidade é que impulsiona a ação do sujeito, ela é o estado emocional do sujeito que é gerado de forma constante no curso de suas atividades. Para ter sentido para o sujeito, toda atividade ou relação implica a existência de uma ou de um conjunto de necessidades.

A aparição dos motivos no sujeito ocorre no momento da identificação do objeto que atende às suas necessidades. Como condição interior de carência do organismo, a necessidade corresponde a um estímulo, uma excitação geral, mas não tem força motivadora. A necessidade só pode ser satisfeita quando encontra um objeto, e essa identificação do objeto - a que chamamos motivo e que se traduz por um conhecimento objetivo - eleva a necessidade ao nível psicológico propriamente dito. A relação entre necessidade e objeto é construída na história de vida de cada indivíduo, portanto a identificação dos objetos e a consequente emergência dos motivos implicam na experiência e no conhecimento de tais objetos. Por ser o motor da atividade - o que a impulsiona, dirige e orienta -, o motivo é síntese do objetivo e do subjetivo. Pensar na motivação é admitir que existe uma relação entre a necessidade - como estado subjetivo - e a identificação do objeto, e que mediando tal processo está um mecanismo de descoberta que se faz por meio da atividade do sujeito.

Assim, o mecanismo produtor de necessidades ou motivações pressupõe a criação de situações em que haja afetação - ou seja, dizer que o conhecimento é efeito de afecções significa reiterar a importância de produzir encontros (Merçon, 2009) que sejam meios de afetar positivamente, criando modos e relações que potencializem o pensar e o agir dos sujeitos afetados.

\section{O LUGAR DA EDUCAÇÃO ESCOLAR NO DESENVOLVIMENTO DO AFETIVO}

A importância do processo educativo como potencializador de novas necessidades humanizadoras decorre do fato de que, à medida 
que impulsiona relações significativas entre o sujeito e o conhecimento dos objetos sociais e das pessoas, por intermédio da atividade da criança, o professor cria possibilidades de afetála positivamente, de mobilizar sua potência para conhecer e atribuir sentidos ao que conhece, atuando inseparavelmente sobre os processos cognitivos e sobre os processos afetivos da criança.

O encontro do sujeito com as objetivações sociais - conhecimentos organizados histórica e socialmente e passíveis de serem compartilhados - poderá ou não produzir o desejo ou a necessidade de conhecer e apropriar-se desse objeto social; entretanto, a apropriação desse conteúdo dependerá de o sujeito empregar ou mobilizar um esforço capaz de reproduzir para ele as características acumuladas nesse objeto social. Neste processo, o sentido pessoal aparece como expressão de uma nova síntese e caracteriza-se por aquela qualidade que a significação social adquire para o sujeito, com base em sua vivência, em sua experiência, e resulta da relação entre apropriação e objetivação do significado ou função social do objeto, como uma fusão do social e do individual, do objetivo e do subjetivo, do cognitivo e do afetivo, na qualidade de uma experiência psicológica. A ênfase na unidade afetivo-cognitiva como princípio pedagógico coloca à educação escolar a tarefa de promover vivências positivas com o conhecimento, de forma a motivar o desejo de conhecer, de se apropriar dos objetos e das formas de relação com as pessoas e de se expressar.

Considerando nosso objetivo primeiro de refletir sobre a constituição dos processos afetivos no conjunto das demais funções psíquicas, entendemos que a criança, com base nas necessidades criadas pelas relações vividas socialmente, inaugura um novo tipo de comportamento à medida que avança em seu desenvolvimento.

A aquisição da linguagem e o crescente domínio e ampliação de processos psicológicos como a percepção, a atenção voluntária e a memória, por exemplo, modificam a relação antes estabelecida entre a criança e a realidade, e a criança passa então a agir diferentemente, demonstrando maior complexificação do pensamento e da conduta. Entre os três e os seis anos de idade o brincar de faz-de-conta surge como atividade principal, e é por meio desse jogo de papéis que a criança vai experimentar um crescente domínio emocional. Esse novo e complexo domínio do conhecimento - o faz-de-conta - emerge da contradição entre a necessidade de agir com os objetos do mundo real como os adultos o fazem, e a impossibilidade de executar ela mesma tais ações (como ela poderá dirigir um carro, conduzir um barco ou cumprir funções profissionais?).

Para resolver esse conflito, a criança, ao escolher seu papel, deverá seguir um roteiro que a cultura lhe estabelece, com ações correspondentes às atuações das pessoas. Nesse processo, ela vai experimentando atitudes compatíveis com cada um dos personagens que imita e vai aprendendo a respeitar as restrições cognitivas e afetivas impostas pelo papel social, o que denota a qualidade histórica dos afetos, bem como a interdependência que estes mantêm com as demais funções psíquicas.

Por serem um mecanismo por meio do qual se pode observar o processo de formação do domínio emocional, os jogos de papéis sociais ou as brincadeiras de faz-de-conta exigem da criança um controle do comportamento que se baseia em regras de condutas sociais, ou seja, o que leva a criança a assumir o comportamento de um personagem que trará implícita uma matriz afetiva. Em outras palavras, para desempenhar um papel é preciso incorporar um "jeito de ser" mãe, irmã, professora, enfermeira e tantos outros diferentes personagens. Esses jogos oferecem à criança a possibilidade de (re)produzir a vivência de maneira integral como unidade de formação cognitiva e afetiva, o que ela faz, também, com base em situações de vida concreta. Isto significa que a criança partirá de situações por ela experienciadas ou conhecidas, e que a ampliação dessas fontes também poderá ser objeto da escola.

Elkonin (1987) faz importantes considerações sobre o jogo na idade préescolar, apoiando a ideia de que os desejos infantis não permanecem inalterados, mas se formam no processo do jogo, de que a forma como se organizam os jogos pode torná-los mais ou menos interessante para as crianças e de que, ao tornar o papel social pleno de conteúdos, tornamo-lo mais atrativo, formamos o desejo da criança. "Esta possibilidade de formar os desejos infantis, de dirigi-los, faz do jogo um poderoso meio educativo quando se introduzem nele temas de grande importância para a educação" 
(p. 101). Assim, o jogo se coloca como um recurso pedagógico para garantir a conquista das formas histórico-sociais da cultura no desenvolvimento ontogenético, a qual é determinada pelos processos de apropriação e pelo domínio das ações socialmente construídas (Vygotski, 1995).

\section{CONCLUSÃO}

Evidentemente, as reflexões sobre a constituição dos processos afetivos no desenvolvimento da criança não se esgotam num único texto, sobretudo se considerarmos a complexidade que envolve a formação humana do sujeito. Assim, coube-nos apenas apontar alguns elementos que entendemos necessários para superar equívocos que ainda persistem quando tratamos das funções afetivas no comportamento humano. Neste processo escolhemos tratar de alguns aspectos que subsistem no contexto educacional, como, por exemplo, o fato de se analisar o afetivo como algo que se acrescenta ao cognitivo, como um elemento ou pré-formação da psique que segue ao lado, facilitando ou dificultando as apropriações da criança na escola ou a conquista de novos conhecimentos que permitam avançar os limites do seu desenvolvimento.

Romper com o pressuposto de que os processos afetivos acontecem naturalmente, como um dado a priori, interno e descolado das relações vivas e dinâmicas que o sujeito estabelece com a realidade, e passar a considerá-los como condicionados pelo conhecimento dos objetos, pelas relações e situações concretas de vida e de educação que a criança vivencia, tem implicações pedagógicas. Uma delas diz respeito à observação do lugar que a criança ocupa nas relações sociais e educacionais que a envolvem e ao modo como organizamos as práticas educativas que são dirigidas para ela.

Defendemos o caráter histórico dos afetos e o fato de estes serem decorrentes de efeitos que nos vêm dos encontros com os objetos culturais (signos e instrumentos), fatos e relações que acontecem durante a nossa existência diária, pois isto é o que mobiliza nosso esforço ou a nossa potência, dando origem à ação e à atividade, e possibilita pensarmos a motivação humana como algo que emerge da atividade que o sujeito realiza. Esta concepção supera a visão constante e homogênea da motivação, pois pensar na motivação para a aprendizagem implica pensar em afetação, em como a criança se encontra com os objetos do conhecimento, como se dá essa relação perpassada por ideias, objetos e fenômenos da realidade escolar, ou seja, como são os elementos mediadores que participam do processo de conhecimento. Mediando a relação da criança com o conhecimento está o adulto, a quem cabe, por isso, um importante papel na criação intencional de situações que promovam necessidades e o desejo do conhecimento. $\mathrm{Na}$ escola esse mediador é, fundamentalmente, o professor.

Sabemos que o que orienta as práticas pedagógicas no terreno da educação escolar são as concepções teóricas e o pensamento dos professores e educadores de modo geral; dito de outro modo, o conjunto de saberes acerca do que é ser criança, dos seus modos de pensar, sentir, fazer, aprender e desenvolver-se é que regula o fazer da educação. Assim, vale a pena indagar sobre alguns elementos orientadores da relação da criança com o conhecimento, como por exemplo: como se dá a acolhida das crianças no dia a dia escolar? Como as atividades são organizadas? Como acontece a distribuição do tempo no cotidiano escolar? Como se elegem os conteúdos que deverão ser trabalhados?

Deixar de lado essas questões pode dificultar a necessária superação da compreensão anistórica dos processos afetivos, que se apresentam como algo do sujeito apenas, como um dado natural e descolado das relações concretas que a criança vive na situação escolar, incorrendo no risco de reproduzir o modelo da psicologia tradicional, que atribui apenas ao aluno as causas de sua aprendizagem e desenvolvimento ou do seu fracasso, além de minimizar a força das relações humanas na produção do sentido que a aprendizagem escolar assume para cada sujeito.

\section{REFERÊNCIAS}

Abbagnano, N. (2007). Dicionário de filosofia. $-5^{a}$ ed. - São Paulo: Martins Fontes.

Deleuze, G.(1978). Aula sobre Espinosa. Recuperado em 22 mar. 2012: http://www.webdeleuze.com 
Elkonin, D. (1987). Problemas psicologicos del juego en la edad preescolar. Em: V. Davídov; M. Shuare, (Orgs.) La Psicologia Evolutiva y Pedagógica en la URSS (Antologia) (pp.83-102). Moscou: Editorial Progresso.

Friedrich, J. (2012). Lev Vigotski: mediação, aprendizagem e desenvolvimento: uma leitura filosófica e epistemológica.Campinas: Mercado de Letras.

Gomes, C. A. V. (2008). O afetivo para a psicologia Histórico-Cultural: considerações sobre o papel da educação escolar. Tese de doutorado, Programa de Pós-Graduação em Educação, Universidade Estadual Paulista, Marília.

Gomes, C. A. V.\& Mello, S. A.(2010). Educação escolar e constituição do afetivo: algumas considerações a partir da Psicologia HistóricoCultural. Perspectiva, 28(2), 677-694.

González Rey, F. L. (2003). Sujeito e subjetividade. São Paulo: Pioneira Thomson Learning.

Leontiev, A. (1978a). Actividad, conciencia y personalidad. Buenos Aires: Ciencias del Hombre.

Leontiev, A. (1978b). O desenvolvimento do psiquismo. Lisboa: Livros Horizonte.

Mangiolino, L. L. S. (2010). Emoções humanas e significação numa perspectiva histórico-cultural do desenvolvimento humano: um estudo teórico da obra de Vigotski. Tese de doutorado, Faculdade de Educação.Universidade Estadual de Campinas. Campinas.

Martins, A. (2009). O mais potente dos afetos: Spinoza e Nietzsche. São Paulo: Martins Fontes.

Marx, K. (1993). Manuscritos econômico-filosóficos. Tradução Artur Morão. Lisboa.
Mello, S. A. (2006). Contribuições de Vigotski para a educação infantil. Em: S.G.L. Mendonça \& S. Miller (Orgs.) Vigotski e a escola atual: fundamentos teóricos e implicações pedagógicas (pp.193-202). Araraquara: Junqueira \& Marin.

Merçon, J. (2009). Aprendizado ético-afetivo: uma leitura spinozana da educação. Campinas, SP: Editora Alínea.

Mukhina, V. (1995). Psicologia da idade pré-escolar. São Paulo: Martins Fontes.

Sawaia, B. B. (2003). Fome de felicidade e liberdade. Em: Centro de Estudos e Pesquisas em Educação, Cultura e Ação Comunitária (Ed.), Muitos lugares para aprender (pp.53-63). São Paulo: CENPEC/Fundação Itaú Social/ Unicef.

Toassa, G. (2009). Emoções e vivências em Vigotski: investigação para uma perspectiva histórico-cultural. Tese de doutorado, Instituto de Psicologia, Universidade de São Paulo, São Paulo.

Vigotski, L.S. (2003). O desenvolvimento psicológico na infância. - São Paulo: Martins Fontes.

Vigotsky, L. S. (2004). Teoria de las emociones. Estúdio histórico-psicológico. Madrid: Akal.

Vygotski, L. S. (1995). Obras escogidas III. Madri: Visor.

Vygotski, L. S. (1996). Obras escogidas IV. Madri: Visor.

Cláudia Aparecida Valderramas Gomes: doutora em Educação pela UNESP/Marília-SP, professora assistente no Departamento de Psicologia Evolutiva, Social e Escolar da UNESP/Campus de Assis-SP. 